Journal of CORPORATE RESPONSIBILITY

AND LEADERSHIP

Corporate Social Responsibility in Management

Theory \& Business Practice

\title{
CSR Maturity Model - Theoretical Framework
}

DOI: http://dx.doi.org/10.12775/JCRL.2017.015

\author{
Ewa GŁuszeK \\ Wrocław University of Economics, Wrocław, Poland \\ e-mail: ewa.gluszek@ue.wroc.pl
}

\begin{abstract}
The article presents the author's model of maturity of corporate social responsibility, which covers two main dimensions: cultural and strategic, and five levels of maturity. Each dimension contains a number of characteristics that describe it, and the description differs for each level. The cultural dimension is related to the concepts of the culture of stakeholders presented by Maon, Lindgreen and Swaen (2010), and previous proposals by Jones, Felps and Bigley (2007), and contains one variable: a stakeholder culture type. The second dimension, strategic, contains two sub-dimensions. The first one is the type of CSR (the distinction between the type of corporate social responsibility), referring to the concepts of Kourula and Halme (2008), and Rangan et al. (2012). The second sub-dimension is the sphere of influence concept, or the limits of corporate responsibility that it is willing to accept - based on Wood's (2012) and Baumol's (1970) concepts. Depending on the company's culture of stakeholders, the type of CSR involved, and the sphere of influence involved, the enterprise can be found at one of five levels of maturity: Elementary, Engaged, Innovative, Integrated, or Transformational.

Purpose: The article is an attempt of conceptualization CSR according to a more dynamic application orientated perspective. The aim is understanding in what way the social responsibility can develop and root in the company's management system. The use of the maturity model will allow managers to determine at what stage of CSR development their company is located.
\end{abstract}


Design/methodology/approach: The research method is based on the analysis of the subject literature and evaluation of the results of the research procedure.

Findings: Depending on the company's culture of stakeholders, the type of CSR involved, and the sphere of influence involved, the enterprise can be found at one of five levels of maturity: Elementary, Engaged, Innovative, Integrated, or Transformational.

Research and practical limitations/implications: The presented model contains only a very general theoretical framework, but will allow for the development of the characteristics in the future and to operationalize them to give managers clear guidance as to what the company is doing well and which practices should still be implemented or further developed.

Originality/value: A different conceptions of organisational development are matching with evolutionary nature of CSR. The main advantage of using the maturity model is the ability to determine at what stage of development the social responsibility of the company is located. Self-assessment with such a model provides managers with the knowledge of what the company is already doing in the field and what areas it should still pay attention to possibly develop its CSR. The theoretical framework for the development of social responsibility presented in the article will also allow for further directions, in-depth empirical research, verifying the consistency of issues contained in particular characteristics (dimensions and levels) and the actual development of such practices in Polish companies.

Paper type: working paper.

Keywords: maturity model, corporate social responsibility, stakeholder culture, CSR type, sphere of influence.

\section{Introduction}

CSR can be perceived as a marginal issue for the company's functioning, but can also be treated as a strategic aim, around which a business model is built. One can take in-between option and try when possible adjust to policy, systems, structures, practice of the company's social responsibility. Maturity models are tools that can help managerial staff make the choice that is consistent with the company's strategy and the environment. They are based on the assumption that different stages of the development of the business encompass different activities, which is related to the level of their skills in the field. Such models show some desirable or logical development paths from an initial state to 
full maturity. They can act as a 'road map' that allows managers to diagnose what skills a company currently owns and which are missing and needed to build to advance in a specific area. It should be noted, that it is not necessary to achieve the highest level of maturity in the future, as there is no universal standard of social responsibility that fits all organisations. Showing different options allows the management of the company to make a more informed choice of specific practices and set a certain path of development, taking into account the local circumstances and the specific nature of the business.

The article is an attempt of CSR conceptualization according to a more dynamic application orientated perspective. The author uses different conceptions of organisational development and matches them with evolutionary nature of CSR. The aim is understanding in what way social responsibility can develop and root in the company's management system. The use of the maturity model will allow managers to determine at what stage of CSR development their company is located.

\section{The essence and meaning of maturity models}

Maturity, which in common means a degree of intellectual, emotional or biological development of an individual, was also referred at the end of the 1970s to an organisation, understanding by it a certain level of ability or perfection in one area. The first maturity grid, published in 1979 by P. Crosby concerned Quality Management Maturity Grid and contained five levels of organisation's skills in using methods and tools of Quality Management. Each organisation could, with the help of a questionnaire estimate a level of its professional skills in using tools and techniques of quality management on the scale from one to five. The grid also showed the path of development, defining what actions should be taken to achieve the next maturity level. Simple and practical logic of the grid was very quickly appreciated by managers. This started the stormy and lasting until now development of grids in many different areas (the most of which refer to process management and project management (Kania, 2013)).

The basic idea on which maturity models are founded (and which was discovered on the basis of research on children's groups and different systems' development including organisations) says that there are different patterns of activities on different levels of development. 
Usually these activities become more complex and sophisticated in progress. The concept of the maturity grid is based on the assumption that identification of a certain pattern of evolution and its changes is possible. This pattern is reflected in another levels and will show a desired and logical development path from an initial state to fully-developed maturity (Poppelbub and Roglinger, 2011). The maturity levels describe next levels of organisational skills, most often from total immaturity, characterised as temporality, lack of organisation and chaos (level 1), through repetitiveness and standardization (level 2), organisation and monitoring (level 3), aware measurement and management (level 4), until continuous practice and improvement, as a display of the highest maturity (level 5). Each of the maturity levels is characterised by the set of different qualities (attributes, skills' areas), and there has to be a logical connection between all levels.

Applications have decided about the popularity of maturity grids in practice. Firstly, they let the company's management establish the present stage of maturity. Secondly, they define the desired level. Thirdly, they show the path how to get to the final level (with the support of the appropriate measures of development). The principal intention, which accompanies preparation for the maturity grids for different areas of management, is mostly diagnosing all skills that a company lacks in a certain area and pointing those, which need to be achieved. In this aspect they can be even compared with a certain kind of a road map supporting continuous practicing of the management of one area (Kania, 2013).

The maturity grids constitute a kind of knowledge compendium from a certain area and a guide for managers, translate this knowledge into concrete practices. Their aim is to change and improve organisations. Maturity grids describe an evolutionary path of development. This path enables organisations to pass from incoherent, at hoc business actions to orderly, monitored and governed ones. The reflection of this path is a hierarchical structure, in which each level of maturity is precisely described by the profile of solutions within strategies, structures, systems, processes and used methods and tools. Each of the levels is a logical consequence of the previous one, being its extension and more and more complex continuation. Maturity grids are made by experts and practitioners, academic community, also by big consulting companies or non-profit associations popularizing tools and techniques often 
used in one field of knowledge, often with the support of government programmes.

Maturity grids can serve for different goals - diagnostics, improvement or comparing with others - that is why there are usually distinguished (Poppelbub and Roglinger, 2011):

- descriptive models - which are used as diagnostic tools to establish the present state and report to management or outer stakeholders (so-called as-is models);

- prescriptive models - which are used as improvement tools, because apart from an identification of the present state describe the desired final one and provide clues concerning next steps to be done and improvement measures (so-called to-be models);

- comparative models - which enable inter or outer benchmarking.

The popularity of model grids is caused by many profits which are the consequence of their usage. Above all these are measurable economic benefits, which may concern e.g.: decreasing costs, shortening the time of doing tasks, increasing productiveness, improving quality, customer satisfaction or index ROI (Goldenson and Gibson, 2003). Another important profits are organisational and managerial ones, more difficult to measure (more intangible), but significantly making work easier for managers and companies. This includes: putting issues in order, integrating techniques and methods into one coherent approach, possibility of using good practices developed by expert teams or the possibility of standardization, measurement, monitoring issues, that so far have been conducted at hoc, chaotically, without coherent frames and any control. On the other hand maturity models cannot be treated as a wonderful cure for all problems and one should to be aware of their weaknesses.

\section{Need to develop a model: The complexity and evolutionary nature of CSR}

There is no doubt that we are witnesses of the CSR progressive institutionalization, which we can clearly observe nowadays. Its symptom are: globalisation of international reporting standards (e.g. GRI) and management standards (e.g. ISO 26000), development of different rankings and ratings estimating companies citizenship, rapid increase of non-government organisations handling social and ecological problems, 
popularisation of pro-societal and ecological actions (also in the delivery chain), development of socially responsible investment funds and constantly expanding legislation and regulations protecting natural environment and encouraging companies to comply with ethical principles and corporate governance rules (Waddock, 2006). In the context of decreasing natural resources, growing environment pollution, climate changes and social global problems (poverty, malnutrition, wars), we must think about this concept as another business megatrend (Lubin and Esty, 2010). In the 1970s and the 1980s, Quality Management (TQM) was a megatrend, in the 1990s it was digitalization (IT). It seems that today we are dealing with the trend of sustainability management ${ }^{1}$. The most important from the company's point of view is the fact that such a 'megatrend' cannot be ignored - it is just 'strategically unavoidable', because it becomes a central factor deciding about a long-term competitive advantage (Lubin and Esty, 2010, p. 3). The nature of such business megatrends is that they force fundamental and long-lasting changes in the way of companies' competition. The sources of these changes can be technological innovations (e.g. IT), social awareness changes (e.g. healthy lifestyle) or new ways of running business (e.g. globalisation, networking).

Over the last few decades, the area of research concerning social responsibility business has become the arena of approaches, ideas, theories and terminology, which often significantly differ from one another, but from the point of practitioners' view are unclear and too complex (Garriga and Melé, 2004). Its peculiar feature alongside complexity is being evolutionary - constant development of its understanding and the range of use. We can say that the term corporate social responsibility is permanently extending, embracing newer and newer areas and ideas achieved on the scientific and practical ground. Basic factors deciding about dynamic evolution of this term are above all historical and cultural contexts and changing social expectations and the consequent legal regulations (Rok, 2013, p. 7). This article assumes the understanding of corporate social responsibility as defined in ISO 26000, which perceives it as the organisation's responsibility for the impact of decisions and actions on society and the environment (PN-ISO 26000, 2012).

${ }^{1}$ This term - with some simplification - we can treat as an equivalent of CSR (cf. Rok, 2013, p. 49). 
If company managers want wisely plan the company social responsibility, they need to have the awareness of what has already been done, and what can be still practically achieved and what actions should be taken. To do this, the knowledge is required. Nevertheless, as the report "Social Responsibility Business in Polish Reality” points out, Polish business people are deprived of that: most of them do not understand (or do not want to understand) what responsible business is. Except for a small group of CSR leaders taking part in an annual responsible companies' ranking, the overwhelming majority of Polish businesses limit their citizenship to sponsoring and occasional charity donations. Polish business deliberately and according to its own needs defines the social responsibility. Although above $65 \%$ of audited firms declare involvement in CSR, the general declarations outweigh the verified data - as stated in the report of the Foundation Centre CSR.PL published in 2015 (Piskalski, 2015).

In this situation, the built self-esteem with the use of maturity grid could enable managers to realise at what stage their company is in reference to attaining the goals and what challenges are ahead of them. It could also help them with establishing some strategic frames for future decisions. Certainly, it should be remembered that the description of practices typical of each level of the maturity grid usually does not correspond exactly to company's reality - normally it turns out that some required practices are performed, but others not. In other words, in some aspects the firm's reality can overtake one level's requirement, but in others quite the contrary - stay behind ${ }^{2}$.

\section{Previous CSR maturity grids}

The gradual maturity grids made with a view to supporting the company managerial staff started to be built only in the last decade. To these models belong the concepts of: Multiple Levels of Corporate Sustainability of Marrewijk and Were (Marrewijk and Were, 2003), the Zadek's Path to Corporate Responsibility (Zadek, 2004), Mirvis' and Googins' Stages of Corporate Citizenship (Mirvis and Googins, 2006) and Maon's, Lindgreen's and Swaen's Consolidative Model of

2 In such situations it is usually assumed that the general maturity level corresponds to the one of the worst achieved practices. 
Corporate Social Responsibility Development (Maon, Lindgreen and Swaen, 2010). All these models have a gradual character and focus on a dynamic, long-term perspective. All of them make the assumption that companies present a very different level of acceptation, understanding and social responsibility rules rooting, and this level changes in the progress of development. So, the authors of these models think that the CSR development process in companies has an evolutionary character, and actions and initiatives taken in its frames change in the progress of time, becoming more integrated with the whole company's management system and responding to the expectations formed by different stakeholder groups.

One of the first CSR maturity models was Zadek's concept. In his opinion, the starting point was the ascertainment that none of the companies become a good citizen during one night. To achieve this - states Zadek - it must go through a long process of five development stages: defensive, compliant, managerial, strategic, and civil (Zadek, 2004). These stages are connected with organisational learning on the basis of social responsibility practice challenges, at the same time, learning this has an organisational and social dimension. The first level - Defensive - it is a negation of existing problematic practices or responsibility for them (defence against attacks that could have negative influence on short-term sale performance, efficiency, brand etc.). The second level - Compliant - it is adjusting, accepting the strategy in accordance with the law, as the unavoidable cost of running own business (medium-term economic value erosion's softening because of reputation and law risk). The third level - Managerial - it is giving managers the responsibility for social issues and their solution and integrating the responsible business practices with operational activity (medium-term economic value erosion's softening and achieving long-term profits). The forth level - Strategic - integrating social issues with key business strategies (strengthening economic values in the long period and gaining advantage of the first player over their rivals). The final fifth level - Civil - it is a wide cooperation in the branch in favour of the social responsibility (strengthening long-term economic value and achieving profits by shared actions). Zadek's offer assumes organisational learning perspective, concentrating mostly on ways of learning by drawing conclusions from immediate experiences (positive and negative) and confronting them with other's experience. The experiences are interpreted, and later coded in the shape of organisational routines driving workers' behaviour. 
Another model - Mirvis's and Googin's one - refers directly to a concept of the organisation's life circle (Greiner's) and treats corporate citizenship development as a gradual process driven by better and better combination of internal skills used to external environmental challenges (Mirvis and Googins, 2006, p. 2). The model includes five levels of citizenship, meanwhile, each of them is described with the help of seven dimensions: Citizenship Concept (how the company understands its role in the society), Strategic Intent (in what degree the citizenship is rooted in the company's strategy, its products, culture and the way of doing business), Leadership (how leaders are informed about citizenship, in what ways they show support and the attitude 'walk the talk'), Structure (how the company citizenship is functionally managed, is it and how it is integrated with other systems, processes, and structures), Issues Management (how the company proactively copes with appearing problems), Stakeholders Relationships (to what degree the company engages its stakeholders) and Transparency (to what extent the firm is open to inform its environment about financial, social and environmental results). The description of another levels of the corporate maturity citizenship: Elementary, Engaged, Innovative, Integrated and Transforming, are included in Table 3.

In turn Maon's, Lingreen's and Swaen's model is built on stakeholders-based corporate social responsibility concept and offers a multivariate perspective, which integrates moral, cultural and CSR strategic development aspects. The authors, on the basis of the previous area models, additionally introduce a stakeholder culture dimension and a social responsiveness dimension, and build the consolidated, 7-staged CSR development model that integrates organisational values and culture with managerial processes and operations (Maon et al., 2010). In their opinion, organisational culture plays the crucial role in the CSR development practices in the company, because the transition to higher stages of development requires from the organisation's members (both at the individually and group levels) good understanding of the concept and internalising the values standing behind it. So, the culture can be either a barrier or a supporter in the social responsibility's rules realization in the company. The CSR rules' integration together with the company's business strategy and rooting them in the management system (e.g. as criteria in taking decisions) requires transformation from the economy-driven culture to the value-driven culture. 
In this context Maon and others suggest that the basic CSR development model's dimension becomes stakeholder culture that can be defined as beliefs, values and practices developed in the processes of solving problems and building relations with stakeholders (Jones, Felps and Bigley, 2007). They use Jones's, Felps', Bigley's typology, which contains the continuity of concern for others - from self-regarding behaviours to other-regarding behaviours (Jones et al., 2007). This typology distinguishes five kinds of the stakeholder cultures:

An Amoral or Agency culture exhibits no concern for others and is based on pure managerial egoism. The Corporate Egoist and Instrumentalist stakeholder cultures represent limited morality cultures which exist under the umbrella term 'moral stewardship'. Regard for others extends only to shareholders in the corporate egoist culture; it includes other stakeholders to the extent that doing so benefits shareholders in the instrumentalist culture. Finally, the Moralist and Altruist cultures demonstrate concern for the welfare of normative stakeholders as a primary motivation, which makes them broadly moral cultures (Jones et al., 2007, p. 144) (see Table 1).

Maon, Lingreen and Swaen think that there is a connection between dominating stakeholder culture and its tendency to react for social expectations which in consequence determines the nature and the range of the CSR development. The authors call their model the consolidative one, as it integrates the previous perspectives: organisational learning (Zadek, 2004) and organisational development (Mirvis and Googins, 2006) with stakeholder culture (based on moral aspects). At the same time they underline the strategic character of the phenomena of the CSR development (Maon et al., 2010, p. 29). In their model, the assumption is that the path of the social responsibility business in moral-culture dimension goes through three main phases: Cultural Reluctance phase, Cultural Grasp and Cultural Embedment (see Table 2). In each of these phases the authors pointed additional stages of development, which have different qualities (all together 7 degrees). In the phase of Cultural Reluctance there is one stage (1) Dismissing; in the phase of Cultural Grasp there are three stages: (2) Self-protecting, (3) Compliance-seeking (4) Capability-seeking; and in the Cultural Embedment there are also three stages: (5) Caring, (6) Strategizing and (7) Transforming (see Table 3). 


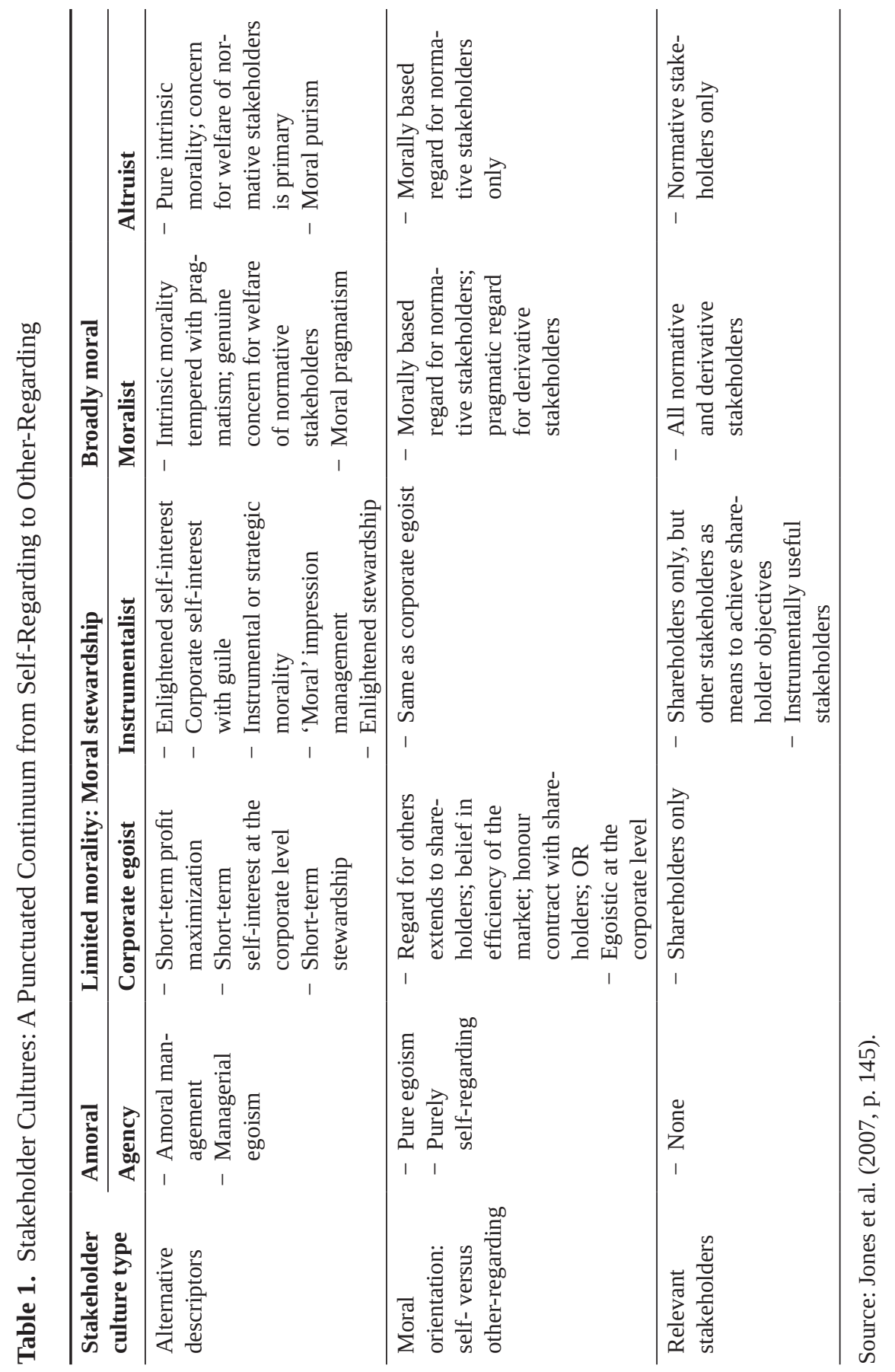




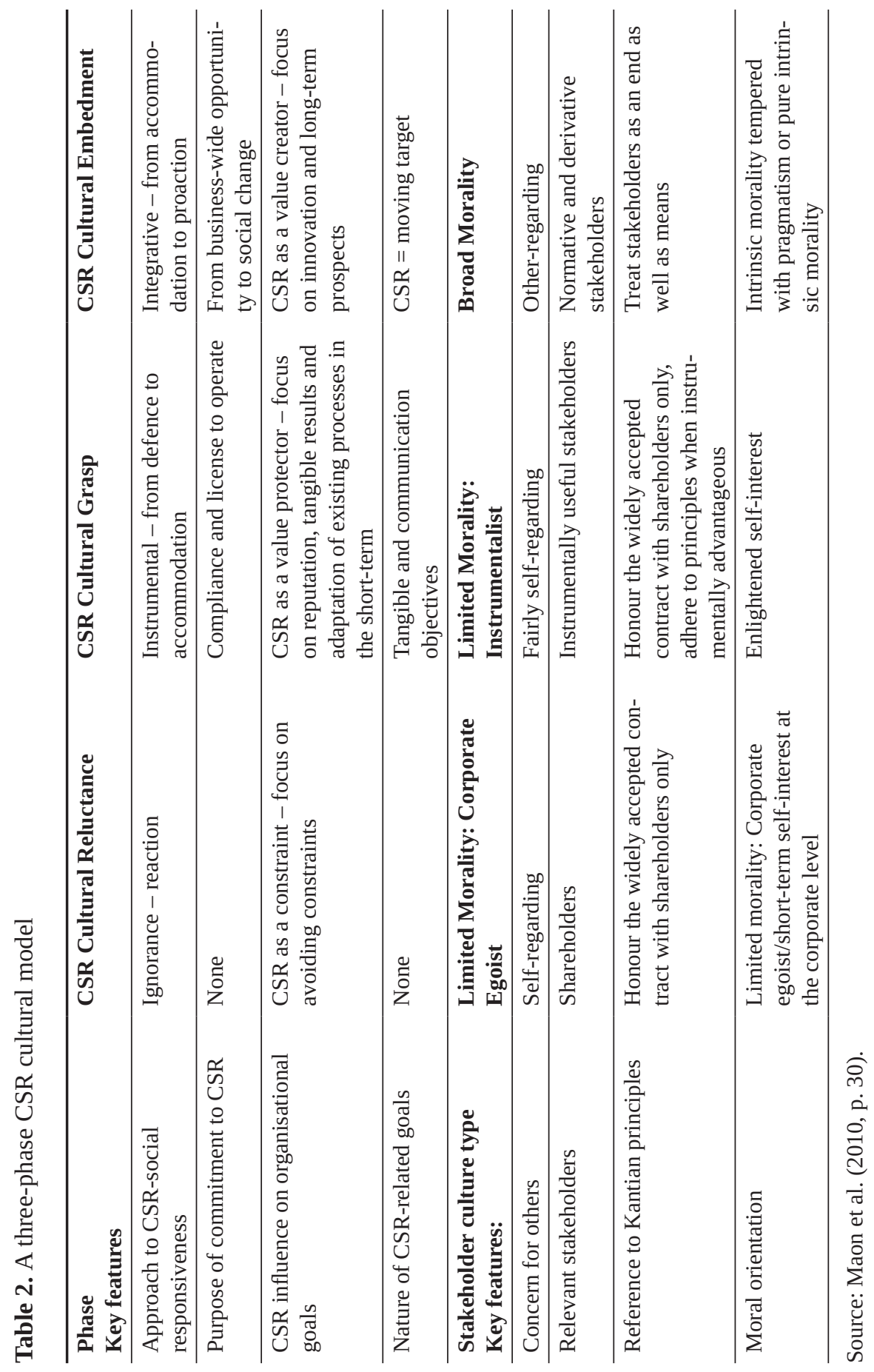




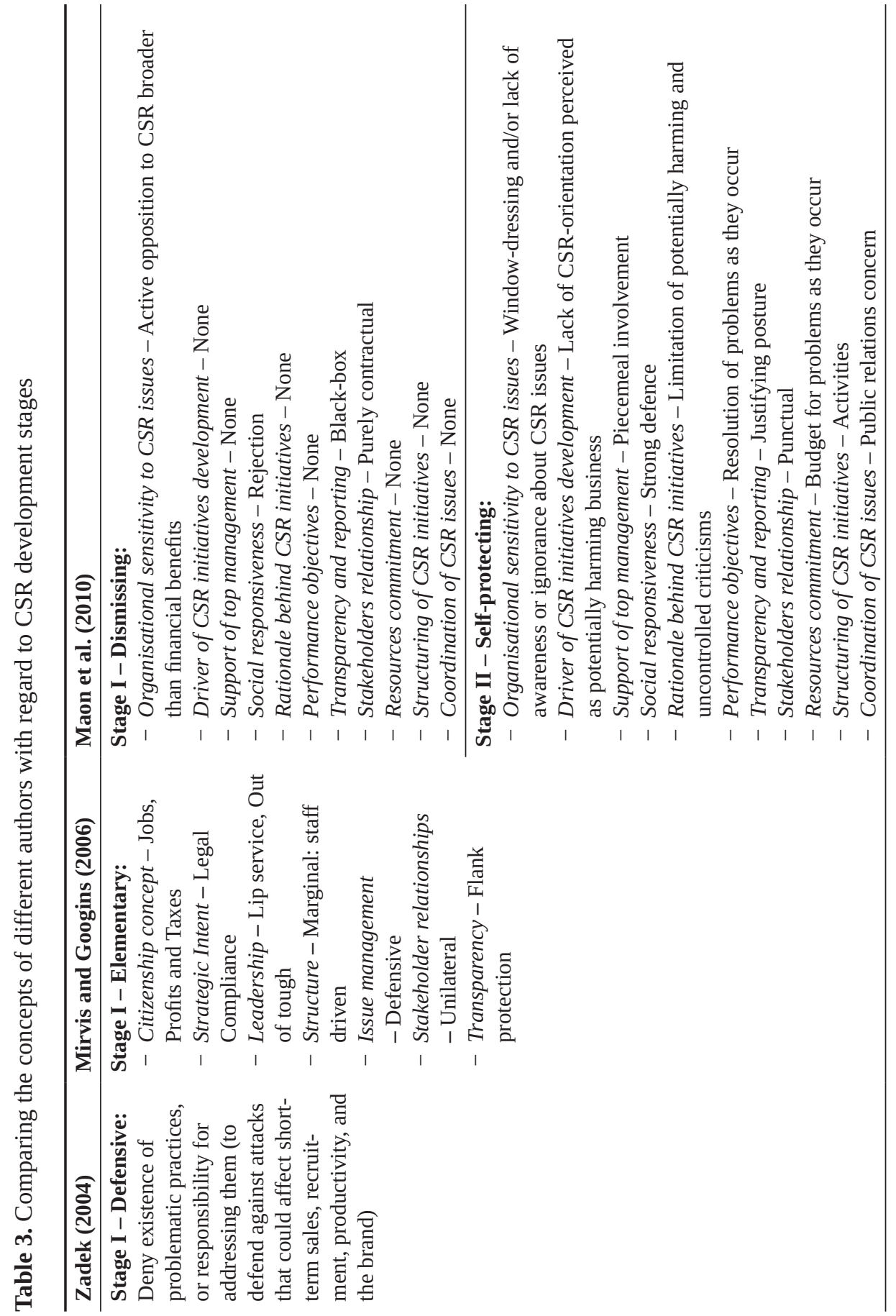




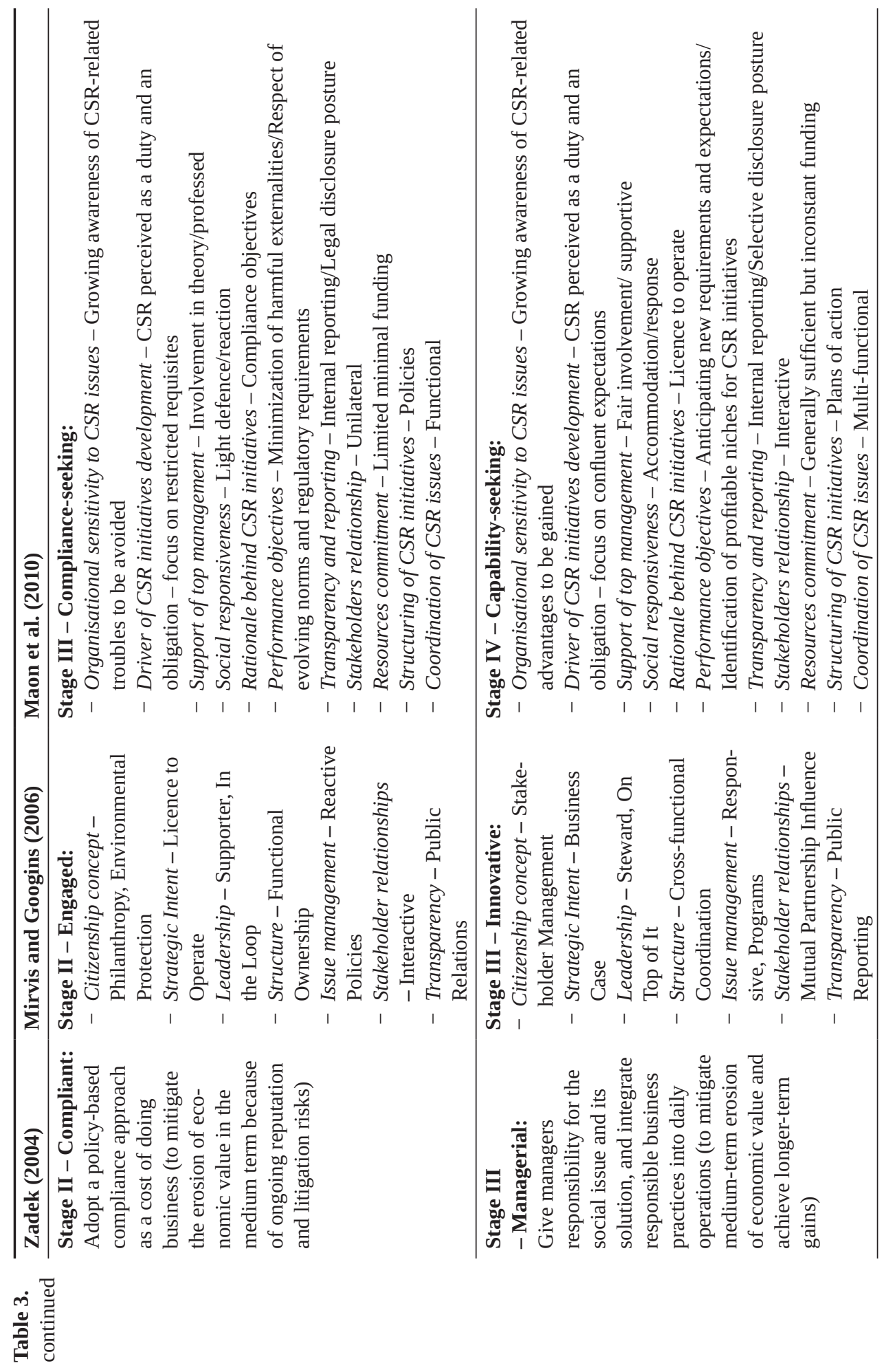




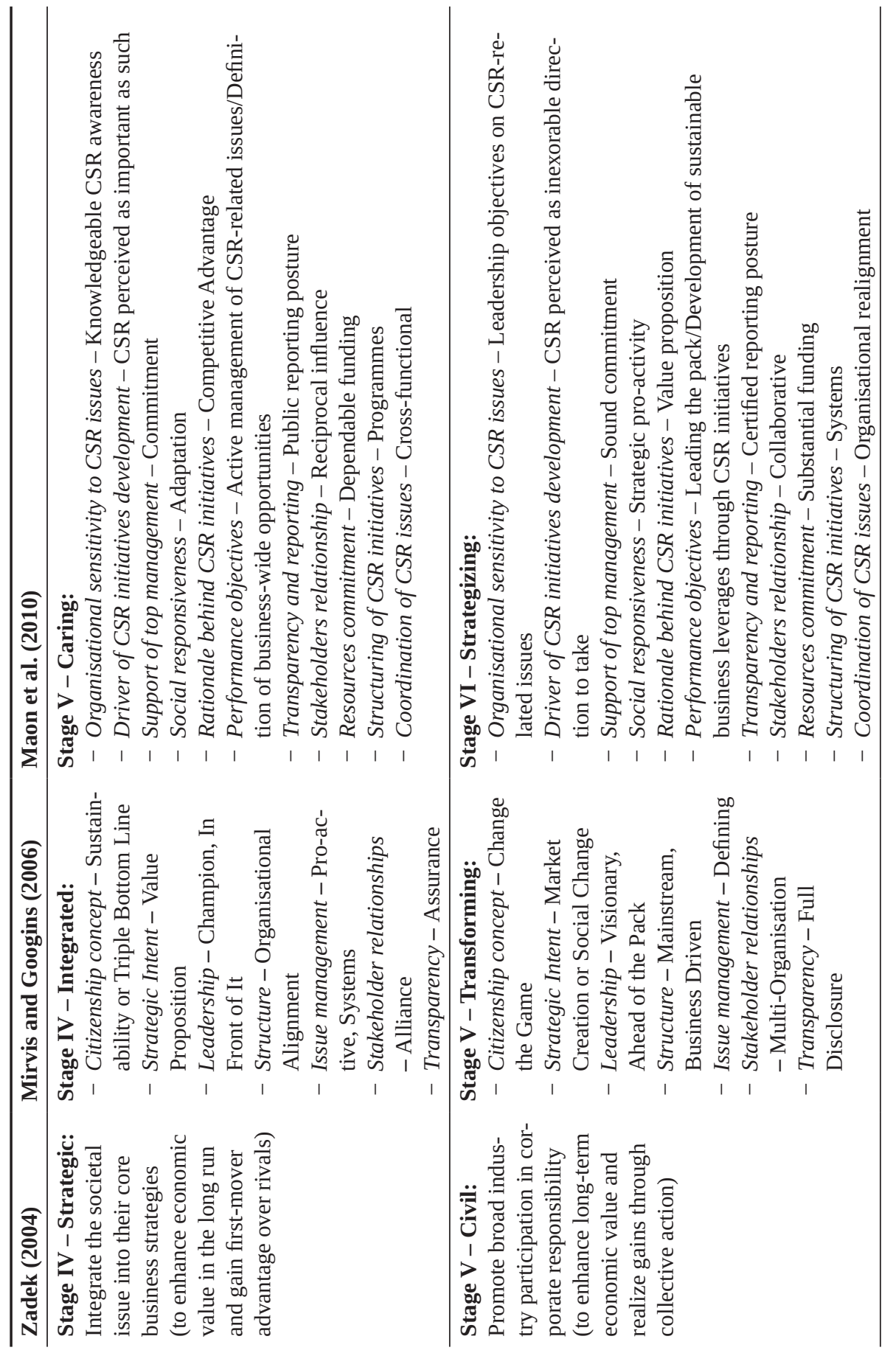

ल 


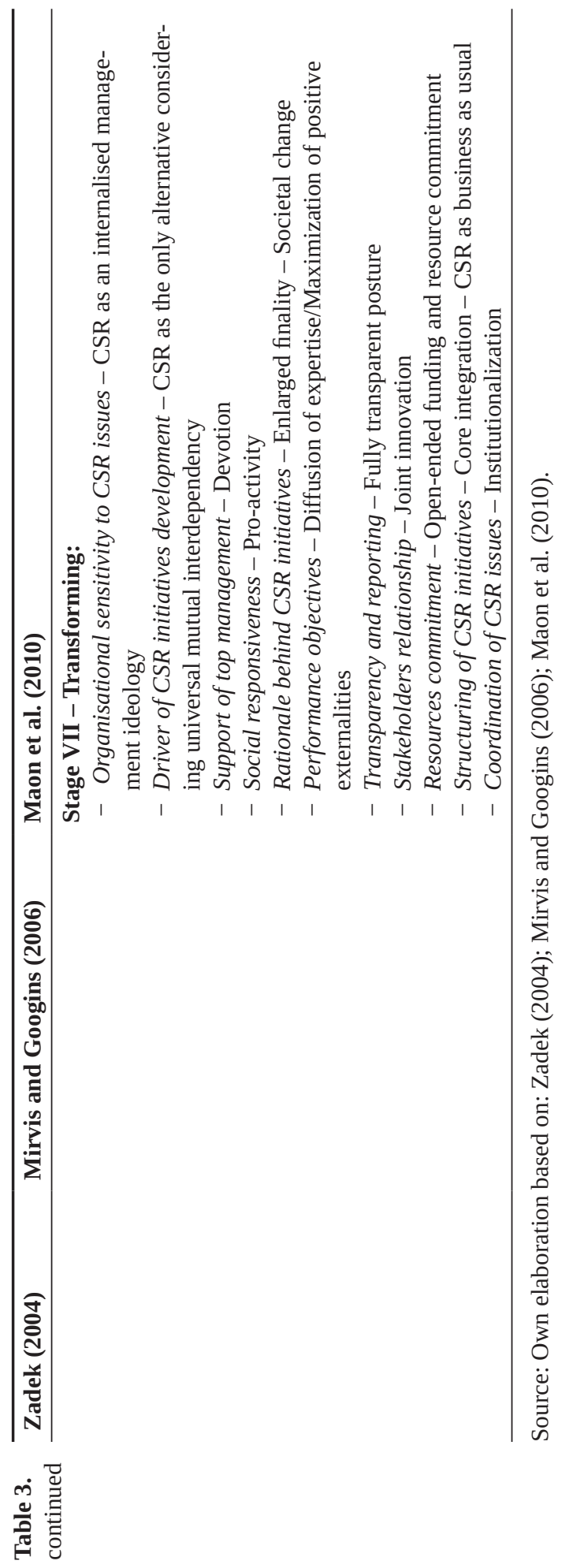


Another stages of social responsibility are described through the practices used by companies in three basic dimensions of the model i.e.: the Attitude and Knowledge - containing: organisational sensitivity to the CSR issues, driver of CSR initiatives development and support from top management; Strategic Dimension including: social responsiveness, rationale behind CSR initiatives, performance objectives and transparency and reporting; Tactical and Operational Dimension: including stakeholders relationship, resources commitment, structuring of CSR initiatives and coordination of CSR issues. As a result it gives more detailed description in what way social responsibility is conducted on each stage of maturity. Table 3 presents comparison of different authors' concepts with regard to CSR development stages.

The presented models try to describe changes that are crucial to integrate CSR rules with the business model and the processes. It is a gradual process in which company skills are gradually used to work out social issues.

\section{Authorial CSR maturity model}

The authorial CSR maturity model originates from the previously described Zadek's, Mirvis's and Googin's, Maon’s et al. proposals. It is based on the principal assumption that various patterns of actions appear on further stages of development, but they are a bit differently understood. They are more complex and sophisticated, too. Not only another policy, procedures and systems emerge on higher maturity levels, but they become more coherent (we can vividly say: from chaotic 'bricks' to 'tightly fitted puzzles'). The increasing variety of activities and structures must be accompanied by orderliness, solidification of coherent and supporting each other programmes that include different CSR aspects. The proposed model has two dimensions: cultural and strategic. The cultural dimension refers to stakeholder culture according to Maon's (Maon et al., 2010) and Jones's understanding (Jones et al., 2010). The strategic dimension owns two aspects (sub-dimensions): the CSR type (relations, operations or innovations) and sphere of influence (SoI). Both of these concepts are relatively new propositions (they appeared in the management literature in the last decade), but because of their importance for contemporary CSR understanding should be included in the domain maturity model. None of these proposals is 
presented by its authors as a concept for the development of CSR, but their increasing complexity allows the author to think of such a staged approach.

In the last years, many researchers dealing with this area have made efforts to integrate its different aspects and they underline the importance of leaving the search of the best way of CSR realisation, they rather suggest integrating various initiatives on the strategic level and the right way of setting priorities and implementing effective managerial instruments (Windsor, 2006; Scherer and Palazzo, 2011; Berger, Cunningham and Drumwright, 2007). In this 'integrating' trend there are the concepts of a certain fundamental distinction between types of CSR, as options that companies have the choice of. They do not expel each other of course (quite contrary - can strengthen and power each other giving synergy effect), but also are not tightly connected (so they do not have to be pursued at the same time). The first such a division was presented by Finish authors - they suggested a distinction of three different types of social responsibility based on pragmatic attitude built on empirical research (Kourula and Halme, 2008). In this case, the impact that CSR exerts on the functioning of the company and society is the basis - in other words it is an attitude based on the dominating model of actions practised by the company. Three types of CSR that can be practised by the companies were identified by the combination of three dimension: in the relation to core business (Porter and Kramer, 2011), the goals of taken actions, and expected benefits (Zadek, 2004). Based on the case study of a few big companies, Kourula and Halme distinguish three principal CSR types that are different in the pointed dimensions. These are: philanthropy, integration with operational action, and innovations (Kourula and Halme, 2008, p. 559).

The extension of Korula's and Halmes's concept is Rangan's, Chase's and Karim's proposal (Rangan, Chase and Karim, 2012). They introduce the idea of the CSR three theatres. The first one includes operations that are motivated by charity, even if they can result in positive business profits. The second theatre represents the CSR actions with the aim of achieving profits for the company and positive social and environmental influence. The third contains the CSR programmes, their essence is a fundamental change of a business 'ecosystem', it is to strengthen a long-term, competitive company's position and to create crucial social value (Rangan et al., 2012). On the basis of their own research, these authors say that the majority of companies very rarely 
coordinate activities in these areas, not to mention the awareness of their meaning for the social well-being. Besides, they do not think that companies should be involved in three kinds of actions, nor they should gradually evolve from one theatre to another. However, they suggest the necessity of maximizing CSR efficiency in this area (or these areas) that is practised by the company and develop a coherent strategy for the entire social responsibility program (it does not matter how many theatres it includes). They also underline that each of the CSR areas is important from the point of view of social and environmental problems (but on different levels - local or global ones) and that not all should bring or will bring quick business result (Rangan et al., 2012, p. 5).

The first CSR theatre - Philanthropic Giving - we can call charity. It can be manifested in the form of e.g. direct donation for a non-profit organisation, sponsoring a social project etc. The corporate philanthropy originates from the belief that a company being an integral part of society has a duty to satisfy some of its needs, bear the social costs of its business and take part in solving the problems. The involvement in CSR comes simply from the belief that it is worth doing it, and the charity given to social institutions (for example NGOs) or a local society is often the reflection of owners' or managers' values. This kind of activity is not connected with core company's competencies and does not translate to the company's economic results. We can only talk about some intangible advantages - strengthening company's reputation and associated risk reduction. With time the business philanthropy can evolve towards the strategic one that is significantly dealt with business priorities and can bring some measurable profits in the long-time perspective (e.g. strengthening of a social capital - educating or retraining local people for future human resources' needs). Despite the possibility of supporting business strategy and potentially positive influence on the results, the first CSR theatre's initiatives are not focused on any business target realisation and should be only estimated through a social profits prism (Rangan et al., 2012, p. 7).

The second CSR theatre - Reengineering the Value Chain - can be called Operations. In contrast to philanthropy this one is concentrated both on increasing profitability and improving business results and creating social and environmental benefits. Operations from this area rely on improving operational effectiveness in the whole company's value chain, beginning with suppliers up to distribution's channels. The principal motivation that accompanies taking actions in this theatre is 
the idea of mutual profits or so-called 'shared value' concept popularised by Porter and Kramer. They say that companies should seek the possibility of creation of such products that give profits both to the company and the society (Porter and Kramer, 2011). It is about e.g. innovative productive and technological solutions that decrease operational costs, and at the meantime soften negative influence on the environment. However, we can say that initiatives of this CSR area are estimated mainly by the prism of improving company's results (Rangan et al., 2012, p. 9).

The third CSR theatre - Transforming the Ecosystem - can be called Innovations. This CSR area of actions relies on radical and wide-scale change of the business model, that in the first place aims to solve a social problem and in the further perspective aims to achieve good financial results and strengthen the company's market position. This may require a fundamental change in the business model, or even the development of new skills, which entails a high level of risk (Rangan et al., 2012, p. 10).

Rangan and others claim that behind each of the three mentioned options lay distinct incentives of the executives and slightly different expected benefits. Business Philanthropy facets indicate mainly 'soft', intangible benefits, such as improved social status of the company, enhancement of the company's reputation and increase in employee motivation. The second type of CSR - Value Chain Reengineering - is more directly connected with the possibility of obtaining earnings or with cost efficiency, which enables determining the triple-bottom line. In this case, managers seek out benefits mostly regarding improvement of the enterprise's environmental impact, the ability to create new business opportunities and to influence the socially sensitive consumers' market, as well as the protection of resources which the company depends on. In the third type of CSR, which involves an Ecosystem Transformation, a great amount of motivation is provided by hopes of long-term gains acquired thanks to a significant change in business environment and to fulfil the social mission formulated by the management board. Among the benefits, however, we can list creating valuable solutions to social and environmental problems, as well as acting on new, significant market opportunities.

The three types of corporate social responsibility described by the authors differ not only in the inducements, which prompt executives of companies to undertake them, but also in the decision makers (people 
in organisation's hierarchy who promote these programs and manage them) and the process of decision making (Rangan et al., 2012, p. 15). According to the studies they conducted, the first Philanthropic CSR type exhibits key roles played by managers responsible for communication or public relations, perhaps CSR managers (if such a position exists in the enterprise), but also individual line managers from various business units. This is understandable if we take into account the fact that these kinds of initiatives are usually characterized by a bottom-up nature and do not have any impact on the company's economic results. In the second type of CSR - Value Chain Reengineering - responsibility shifts in the direction of production, quality management, marketing managers and others, although managers of community affairs also tend to get involved in the program's execution. In this type, initiatives can stem from various areas and levels of management and may influence the firm's performance, and are therefore managed in top-down fashion. However, in the case of the third type of CSR involving Ecosystem Transformation, due to its strategic nature and significance to the company, decisions are made and leaded on from the highest level of management, i.e. the CEO, executive director, etc.

The second strategic aspect of a suggested maturity model, next to CSR type, are Spheres of Influence (SOI) - in other words, the boundaries of a firm's responsibility. This is an extremely crucial factor from the perspective of executives, who are responsible for undertaking initiatives regarding CSR, as it concerns the fundamental issue of the debate on: where corporate social responsibility reaches its limit, in the spectrum of human rights, for instance. Does this responsibility apply to the sphere of influence restricted to particular activity run directly by the company, as it is defined by the Global Compact rules, or - as it is required by today's standards (e.g. ISO 26000) - should the term Sphere of Influence (regarding, among others, embracement of human rights, protection of the environment, fair trading classes and consultation with consumers) be expanded to the possibility of indirect impact of a company, meaning its entire value chain? The issue of voluntariness of such an activity also sparks strong controversy, as it has been, up until now, one of corporate social responsibility's main rules. The current standards clearly depart from discretionary moral duty and aim at obligatory compliance with certain ethical principles (e.g. human rights) and establishing it as a binding, minimal standard of conduct, which companies should be held accountable for (Ruggie, 2011). 
In the ISO 26000 guide, a sphere of influence is defined as a wide range of political, contractual, economic and other relationships through which an organisation has the power to influence the decisions or behaviours of individuals or organisations. However, the boundaries of the organisation's responsibility have not been specifically outlined, leaving the matter open for discussion and only drawing attention to the fact that the ability to influence something is not quite the same as claiming responsibility for that influence. Companies may have impact by conducting dialogues with stakeholders, spreading knowledge and promoting good educational programs, making investment decisions, relations with the media, etc. This impact can have either a direct or indirect nature, which has been pointed out already in the 1970s by Baumol, who composed a full, intact CSR model for the first time (Baumol, 1970, cited after: Rok, 2013, p. 34). Three fields of responsible management appeared in his concept: (1) basic internal responsibility for gaining profit, creating work places and offering high quality products, (2) intermediate liability, to minimize the negative consequences of your own business, which is response to the public's expectations and (3) external responsibility concerning undertaking initiatives that contribute to the improvement of the social environment in which the company is situated.

In addition to impact, organisations' decisions and actions may also involve leverage. This is understood as the ability of a company to contribute to improving the situation by exerting pressure on other actors within the framework of connecting them (Wood, 2012). Subjection to leverage should be taken under account in determining who is responsible for abiding by human rights - for example, whether a company should take responsibility for the work conditions of its suppliers. According to Wood applying leverage may and should be a cause for corporate responsibility if the following four requirements are met: (1) there is a significant moral relationship between the company and the rights-holder or rights-violator, resulting from the relations that bond them, (2) the company can contribute to improving a given situation in a significant manner (independently or with other entities), (3) can achieve this by acceptable costs and (4) if the threat to human rights is serious. In such circumstances a corporation is responsible for using leverage, even if it was not the one who contributed to perpetrating the given situation. This understanding of responsibility refers to "the iron rule of responsibility" formed by Davis, which conditions 
the level of responsibility of a company to its influencing abilities. This means that the more power and control a firm has over a given situation the greater its responsibility for it (Davis, 1975, cited after Wood, 2012).

Wood also indicates the fact that responsibility can be of positive character, meaning 'doing good', but also negative which should be understood as 'not causing harm'. In the earlier mentioned Baumol's concept the first and third range of responsibility are therefore of positive character, the second, however, of negative. Considering the already contrived distinction between exerting influence and exerting leverage, the decisions and actions of a company fall into one of four possible situations (Wood, 2012). The first kind is Impact-based positive responsibility which is based on claiming responsibility for having a positive effect on society or the environment (directly or through business relations). The second is Impact-based negative responsibility, meaning responsibility for causing an undesired immoral social or environmental effect to occur (directly or through business relations). The third situation is Leverage-based positive responsibility - to use their leverage to increase or maximize the positive social or environmental impacts of other actors with whom they have relationships. The last, fourth, situation involves Leverage-based negative responsibility - for applying leverage on other entities which the organisation remains affiliated with to prevent their actions from causing unwanted social and environmental effects.

It can be stated that subjecting other organisations to leverage as a way of putting pressure on them is an expansion of the concept of having impact. As much as the first referred to being held accountable for one's corporate impact on society or the environment, the latter de facto refers to exerting influence intermediately on entities which are affiliated with the corporation (not necessarily in a business matter) in order to improve a situation, reduce harm and default, but also to protect, promote and abide by human rights (Wood, 2012). The distinction between exerting impact and applying leverage may seem very subtle and insignificant, but in reality it helps to decide who holds obligations regarding the spectrum of human rights. A key role in determining the range of responsibility is played by the strength of ties which the company makes through its actions - the larger the firm, higher market position, more developed network of relations and greater ability to have an impact - the greater its responsibility. 
The author's model of CSR development described in this chapter encompasses two main dimensions: cultural and strategic, as well as five maturity levels: Elementary, Engaged, Innovative, Integrated and Transforming. Both of these dimensions contain a list of characteristics which describe them and, on top of that, differ on each stage. The first, cultural dimension refers to the concept of stakeholders' culture, formulated by Maon, Lindgreen and Swaen (Maon et al., 2010), as well as the earlier model suggested by Jones, Felps and Bigley (Jones et al., 2007), and it contains one variable: the type of stakeholder culture. In this aspect - according to Jones' concept - five types of stakeholder culture have been distinguished, which correspond to five different levels of maturity. They fall into three phases: Amoral, Limited morality and Broad morality. The Amoral phase consists of one type of culture known as the Agency type. The Limited morality phase contains two culture types: Corporate egoist and Instrumentalist, similarly to the Broad morality phase which also has two types of stakeholder culture - named Moralist and Altruist (Wood, 2012). Each one of these culture types is characterized with the aid of the following four criteria: Approach to CSR - social responsiveness, Leadership - support of top management, Purpose of commitment to CSR and CSR influence on organisation goals.

The second, strategic dimension holds two sub-dimensions (sub-aspects): type of CSR and sphere of influence. The first of them is divergence regarding the type of corporate social responsibility in reference to the concept formulated by Kourula and Halme (2008), as well as Rangan's (Rangan et al., 2012). This aspect again contains five CSR types which correspond to five maturity levels: Ignorance, Philanthropy, Strategic Philanthropy, Value Chain Reengineering and Transforming the Ecosystem. The types of CSR are described by five key characteristics: Strategy of value creation, Stakeholders relationship, Structuring of CSR initiatives, Coordination of CSR issues and Transparency. The latter of the sub-dimensions concerns a company's spheres of influence, meaning the boundaries of responsibility that it is ready to commit to. Five spheres of influence, which again correspond to five maturity stages, have been distinguished in accordance with Wood's (2012), as well as Baumol's (1970, after: Rok, 2013), concepts: Internal impact-based responsibility, Impact-based negative responsibility, Impact-based positive and negative responsibility, Impact-based positive and negative responsibility and leverage-based negative responsibility; Impact-based positive and 
negative responsibility, and leverage-based positive and negative responsibility. The sub-dimension of responsibility boundaries is characterized by two indicators: what the company cares about and whom the company influences. The CSR maturity model is presented in Table 4.

The first level of the CSR maturity model - Elementary - is really the ground level which in reality holds no real activity in accordance with social responsibility rules. The author decided to take this step into account due to the fact that most Polish companies fulfil the notion of CSR either in a very limited way, if they even do it at all (Piskalski, 2015). The first stage of the cultural aspect represents the Amoral phase of stakeholder culture (Agency) which is characterised by ignoring the facets of social responsibility or openly negating them. In this case, CSR is considered as restriction of corporate activity which should be avoided at all costs. In the strategic aspect this level does not represent any type of CSR because the relations with stakeholders are purely contractual. In the aspect of sphere of influence companies which are at this initial stage are usually only willing to accept internal responsibility, of economic nature - for generating profit, creating work places and enhancing product quality.

The second maturity level - Engaged - is the Limited morality phase in the cultural dimension with its corresponding type of stakeholder culture named Corporate Egoist. It is characterised by a growing awareness of social responsibility norms, especially in the context of growing societal problems and needs which could be avoided by following the rules of CSR. In this stage we can observe certain incidental commitment of the firm's executives who are willing to accept some social initiatives, especially since social benefits bring other attributes along with them, like improvement of the company's image or winning the approval of the local community. In the strategic dimension this kind of commitment has been called Philanthropy. Here, strategy assigns CSR the role of value protector, as it is meant to focus on moderating costs and avoiding draining resources. The relationship with stakeholders has a one-sided nature and coordination of charity initiatives is typically conducted through communication or public relations departments. In reference to the second sub-aspect, this maturity level states that the company is mainly concentrated upon minimising any of its activity's possible negative effects.

The third level of maturity - Innovative - further represents the Limited morality phase of the cultural aspect. The Instrumentalist type 


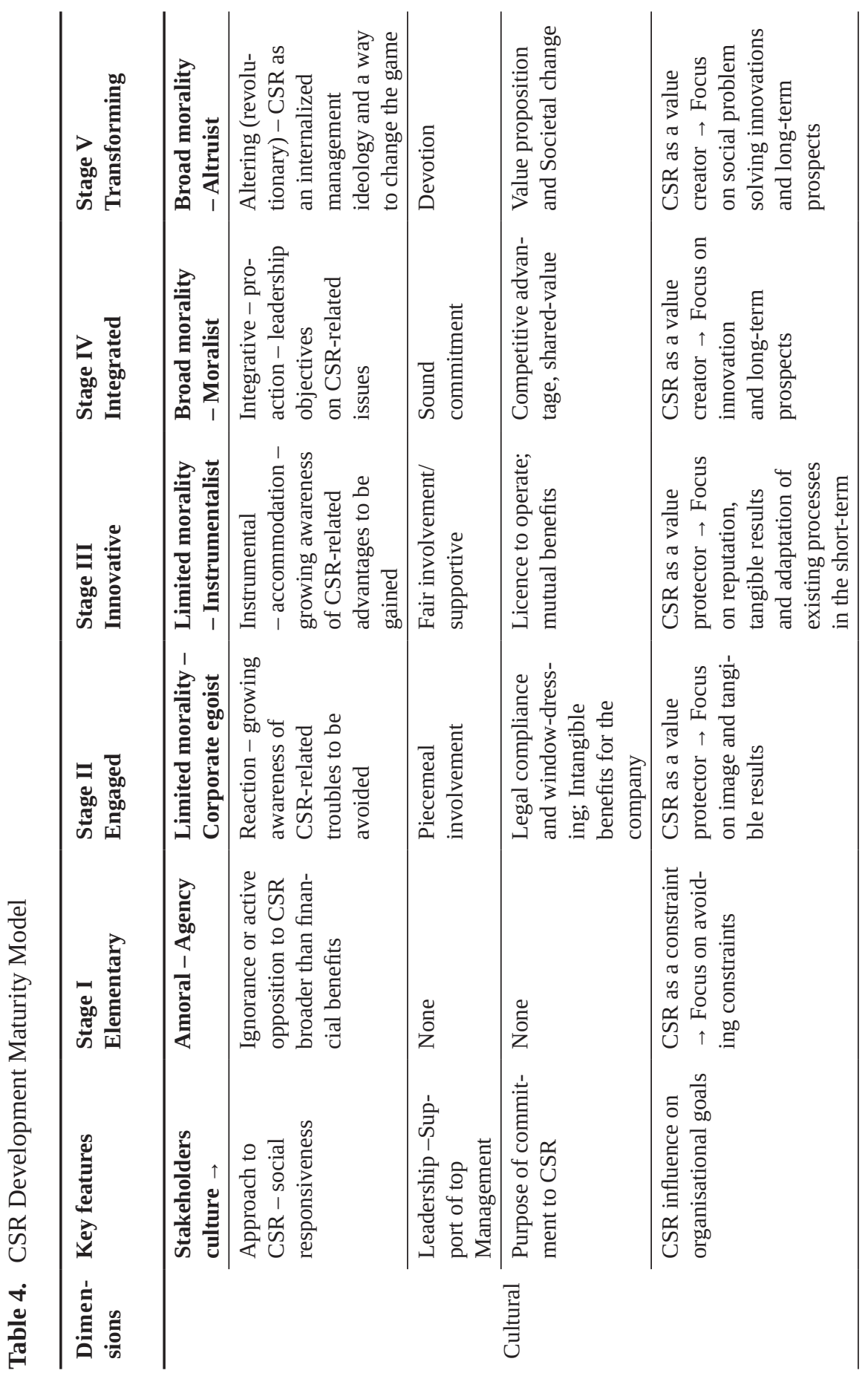




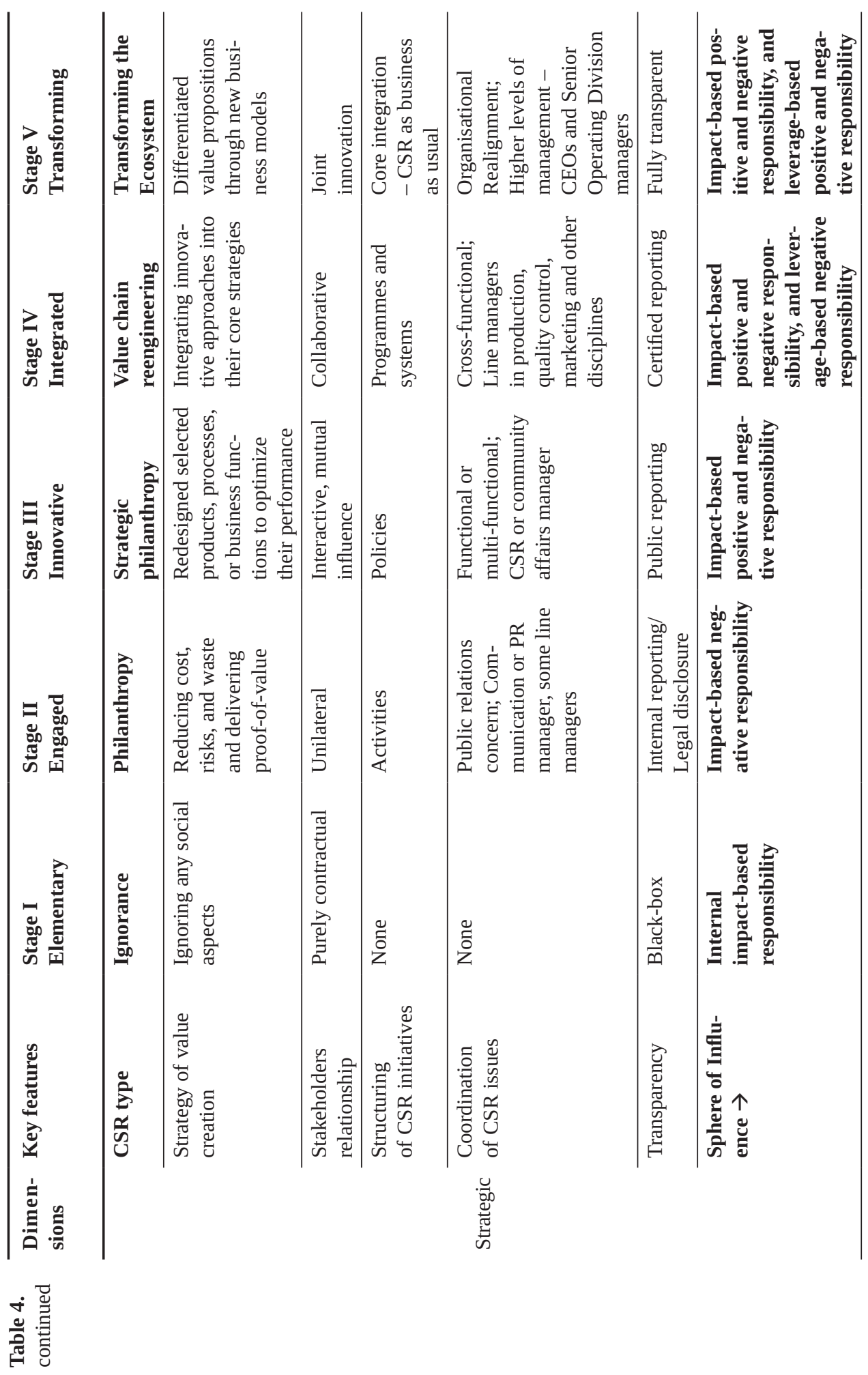




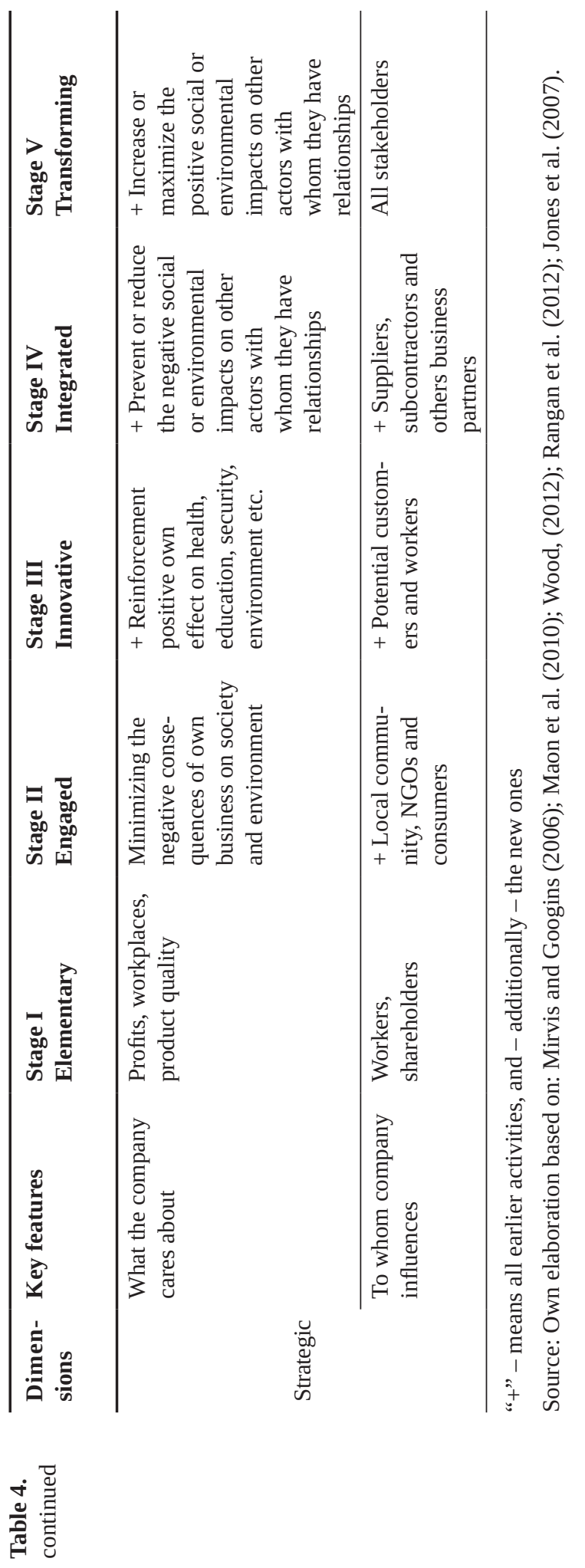


of stakeholder culture - as the name suggests - is characterized by an instrumental approach to CSR, based on a firm's willingness to indulge in social issues due to specific benefits and advantages that come with such a conduct. The management's involvement on this level is quite significant - the top management supports CSR initiatives, knowing that they provide a license to operate for the company and that they can bring perceivable economic benefits. The type of CSR being fulfilled at the third level of maturity has been labelled as Strategic Philanthropy. It involves redesigning some products or processes in such a way that they serve society (solve a certain social problem), but, at the same time, bring specific benefits to the company. Here, the relationship with stakeholders has a double-sided interactive nature, the initiatives are coordinated inter-functionally through the CSR or community affair manager and written about in publicly available reports. The sphere of influence is restricted to minimising negative consequences of corporate activity and strengthening the positive ones.

The fourth level of CSR maturity - Integrated - is a shift to the Broad morality phase and the culture of stakeholders defined as Moralist. Corporate social responsiveness is strongly proactive, as the goals of social responsibility are incorporated into strategic goals, and the management is committed to achieving them. The main motive for engaging a company in CSR practice is the desire to gain competitive advantage based on the so-shared value concept (economic-social value), which consists in the production of economic value in a way that simultaneously creates social value, meeting the needs and problems of society (Porter and Kramer, 2011, p. 38). Innovation (shared value) becomes the source of creating new value (and not just its protection) and is not just a margin of business, but its core. The kind of CSR at this level of maturity can be called value chain reengineering, which involves implementing innovation throughout the value chain and integrating them into the core competencies of the company. This approach to social responsibility requires not only policy but consistent, well-thought-out programs and systems and cross-functional coordination. The sphere of influence of the company here is considerably extended from the previous stage to leverage-based negative responsibility (exert pressure on other entities that are in a relationship in order to prevent or reduce their adverse or harmful effects on social or natural environment) - most often, companies are up or down the value chain (suppliers, subcontractors, customers, etc.). 
The last, fifth level of maturity - Transformational - represents the Broad morality and culture of the stakeholders called Altruist. Social responsibility is treated as a fully internalized management theory that can change the rules of the market game. Its main goal is to create a new business model, based on the merge of profit with the societal good, which enables faster social progress while allowing companies to grow further. In this way, positive corporate prosperity is coupled with the wellbeing of a local or global community, resulting in profitable long-term returns (Porter and Kramer, 2011, p. 54). CSR at the highest level of maturity was termed Ecosystem Transformation. It requires full integration with key business activities and the coordination of diverse practices, which requires organisational realignment and commitment of the highest levels of management. The sphere of influence is widened by another circle - leverage-based positive responsibility (positive pressure on the actors in the network of the company's relationship), in order to cause some positive impact on society or nature.

\section{Conclusions}

The article presents the author's model of maturity of corporate social responsibility, which covers two main dimensions: cultural and strategic, and five levels of maturity. Each dimension contains a number of characteristics that describe it, and the description differs for each level. The cultural dimension is related to the concepts of the culture of stakeholders presented by Maon, Lindgreen and Swaen (2010), and previous proposals by Jones, Felps and Bigley (2007), and contains one variable: a stakeholder culture type. The second dimension, strategic, contains two sub-dimensions: the type of CSR (the distinction between the type of corporate social responsibility), referring to the concepts of Kourula and Halme (2008), and Rangana (Rangan et al., 2012), and the sphere of influence concept, or the limits of responsibility that it is willing to accept - based on Wood's (2012) and Baumol's (1970, after: Rok, 2013) concepts. Depending on the company's culture of stakeholders, the type of CSR involved, and the sphere of influence involved, the enterprise can be found at one of five levels of maturity: Elementary, Engaged, Innovative, Integrated, or Transformational.

The main advantage of using the maturity model is the ability to determine at what stage of development the social responsibility of the 
company is located. Self-assessment with such a model gives management the knowledge of what the company is already doing in the field and what areas it should still pay attention to possibly develop further CSR. The presented model contains only a very general theoretical framework, but will allow for the development of the characteristics in the future and to operationalize them to give managers clear guidance as to what the company is doing well and which practices should still be implemented or further developed. The theoretical framework of the development of social responsibility presented in the article will also allow for further in-depth empirical research, verifying the consistency of issues contained in particular characteristics (dimensions and levels) and the actual development of such practices in Polish companies.

\section{References}

Baumol, W.J. (Ed.) (1970), A New Rationale for Corporate Social Policy, Committee for Economic Development (CED), New York.

Berger, I.E., Cunningham, P., Drumwright, M.E. (2007), “Mainstreaming Corporate Social Responsibility: Developing Markets for Virtue”, California Management Review, Vol. 49, Issue 4, pp. 132-157.

Davis, K. (1975), "Five Propositions for Social Responsibility”, Business Horizons, Vol. 18, Issue 3, pp. 19-24.

Garriga, E, Melé, D. (2004), “Corporate Social Responsibility Theories: Mapping the Territory”, Journal of Business Ethics, Vol. 53, Issue 1-2, pp. 51-71.

Goldenson, R., Gibson, D. (2003), Demonstrating the Impact and Benefits of CMMI ${ }^{\circledR}$ : An Update and Pre-liminary Results, Special Report. Retrieved from http://ralphyoung.net/articles/PI_Results_SEI.pdf (accessed 09 January 2018).

Jones, T., Felps, W., Bigley, G. (2007), “Ethical Theory and Stakeholder-Related Decisions: The Role of Stakeholder Culture”, Academy of Management Review, Vol. 32, No. 1, pp. 137-155.

Kania, K. (2013), Doskonalenie zarzq̨dzania procesami biznesowymi w organizacji z wykorzystaniem modeli dojrzałości i technologii informacyjno-komunikacyjnych, Uniwersytet Ekonomiczny, Katowice.

Kourula, A., Halme, M. (2008), “Types of Corporate Responsibility and Engagement with NGOs: An Exploration of Business and Societal Outcomes”, Corporate Governance, Vol. 8, Issue 4, pp. 557-570.

Lubin, D., Esty, D. (2010), “The Sustainability Imperative”, Harvard Business Review, Vol. 88, No. 5, pp. 42-50.

Maon, F., Lindgreen, A., Swaen, V. (2010), “Organizational Stages and Cultural Phases: A Critical Review and a Consolidative Model of Corporate Social Responsibility Development”, International Journal of Management Reviews, Vol. 12, Issue 1, pp. 20-38.

Marrewijk, M., Were, M. (2003), “Multiple Levels of Corporate Sustainability”, Journal of Business Ethics, Vol. 44, Issue 2-3, pp. 107-119. 
Mirvis, P., Googins, B. (2006), Stages of Corporate Citizenship: A Developmental Framework, A Center for Corporate Citizenship at Boston College Monograph, Boston.

Piskalski, G. (2015), Społeczna odpowiedzialność biznesu w polskich realiach: Teoria a praktyka, Fundacja CentrumCSR.PL, Warszawa.

PN-ISO 26000 (2012), Wytyczne dotyczq̨ce społecznej odpowiedzialności, Warszawa.

Poppelbub, J., Roglinger, M. (2011), "What Makes a Useful Maturity Model? A Framework of General Design Principles for Maturity Models and Its Demonstration in BPM", paper presented at the $19^{\text {th }}$ European Conference on Information Systems (ECIS), 9-11 June 2011, European Research Center for Information Systems (ERCIS), University of Münster. Retrieved from http://fim-rc.de/Paperbibliothek/ Veroeffentlicht/327/wi-327.pdf (accessed 09 January 2018).

Porter, M., Kramer, M. (2011), “Tworzenie wartości dla biznesu i społeczeństwa”, Harvard Business Review Polska, No. 5(99).

Rangan, K., Chase, L., Karim, S. (2012), "Why Every Company Needs a CSR Strategy and How to Build It”, HBS Working Paper No. 12-088, 5 April.

Rok, B. (2013), Podstawy odpowiedzialności społecznej w zarzqdzaniu, Poltext, Warszawa.

Ruggie, J. (2011), "Report of the Special Representative of the Secretary-General on the Issue of Human Rights and Transnational Corporations and other Business Enterprises”, Netherlands Quarterly of Human Rights, Vol. 29, Issue 2, pp. 224-253.

Scherer, A., Palazzo, G. (2011), “The New Political Role of Business in a Globalized World: A Review of a New Perspective on CSR and Its Implications for the Firm, Governance, and Democracy”, Journal of Management Studies, Vol. 48, Issue 4, pp. 899-931.

Waddock, S. (2006), "Building the Institutional Infrastructure for Corporate Social Responsibility”, Harvard University Working Paper No. 32, December.

Wood, S. (2012), “The Case for Leverage-Based Corporate Human Rights Responsibility”, Business Ethics Quarterly, Vol. 22, Issue 1, pp. 63-98.

Windsor, D. (2006), “Corporate Social Responsibility: Three Key Approaches”, Journal of Management Studies, Vol. 43, Issue 1, pp. 93-114.

Zadek, S. (2004), “The Path to Corporate Responsibility”, Harvard Business Review, Vol. 82, No. 12, pp. 125-132. 